\title{
Probiotic strain Bacillus subtilis CU1 stimulates immune system of elderly during common infectious disease period: a randomized, double-blind placebo-controlled study
}

\author{
Marie Lefevre ${ }^{1 *}$, Silvia M. Racedo ${ }^{2}$, Gabrielle Ripert ${ }^{2}$, Béatrice Housez ${ }^{3}$, Murielle Cazaubiel ${ }^{3}$, Corinne Maudet ${ }^{3}$, \\ Peter Jüsten ${ }^{1}$, Philippe Marteau ${ }^{4}$ and Maria C. Urdaci ${ }^{2}$
}

\begin{abstract}
Background: Bacillus probiotics health benefits have been until now quite poorly studied in the elderly population. This study aimed to assess the effects of Bacillus subtilis CU1 consumption on immune stimulation and resistance to common infectious disease (CID) episodes in healthy free-living seniors.

Results: One hundred subjects aged 60-74 were included in this randomized, double-blind, placebo-controlled, parallel-arms study. Subjects consumed either the placebo or the probiotic $\left(2.10^{9}\right.$ B. subtilis CU1 spores daily) by short periodical courses of 10 days intermittently, alternating 18-day course of break. This scheme was repeated 4 times during the study. Symptoms of gastrointestinal and upper/lower respiratory tract infections were recorded daily by the subjects throughout the study (4 months). Blood, saliva and stool samples were collected in a predefined subset of the first forty-four subjects enrolled in the study. B. subtilis CU1 supplementation did not statistically significantly decrease the mean number of days of reported CID symptoms over the 4-month of study (probiotic group: 5.1 (7.0) d, placebo group: 6.6 (7.3) d, $P=0.2015$ ). However, in the subset of forty-four randomized subjects providing biological samples, we showed that consumption of B. subtilis CU1 significantly increased fecal and salivary secretory IgA concentrations compared to the placebo. A post-hoc analysis on this subset showed a decreased frequency of respiratory infections in the probiotc group compared to the placebo group.
\end{abstract}

Conclusion: Taken together, our study provides evidence that B. subtilis CU1 supplementation during the winter period may be a safe effective way to stimulate immune responses in elderly subjects.

Keywords: Clinical trial, Elderly, Common infectious disease, Probiotics, Immunostimulation

\section{Background}

Viral respiratory and gastrointestinal infections are a predominant cause of morbidity and mortality in the elderly whose ageing immune system contributes significantly to poor outcomes [1]. Ageing is associated with a decline of innate and adaptive immune responses. For innate dysfunction, it has been described that the function of natural

\footnotetext{
*Correspondence: mle@ennolys.fr

'Lesaffre Human Care, Lesaffre Group, 278 Avenue de la Marne, Château rouge, 59700 Marcq en Baroeul, France

Full list of author information is available at the end of the article
}

killer cells, dendritic cells [2], macrophages [3] and neutrophils [4] decrease in the elderly. Moreover, agedependent thymic involution leads to the reduction of circulating naive $\mathrm{T}$ cells and the increase frequency of regulatory, memory and effector $\mathrm{T}$ cells $[5,6]$. A dramatic reduction in $\mathrm{B}$ cell repertoire associated with a decreased systemic antibody response to vaccination has been observed in the elderly population [7] showing that the $\mathrm{B}$ cell compartment is also affected by ageing $[8,9]$. In addition, the production of secretory IgA (SIgA) at the mucosal surfaces decreases with age 
and can lead to an increased risk of infection [10, 11]. SIgA, the predominant immunoglobulin class in human external secretions, is a key element in the maintenance of gut microbiota homeostasis and in the protection of gastrointestinal and respiratory tracts against pathogens [12]. Moreover, it has been also shown that the agedependent modifications of the composition of the gut microbiota also contribute to the defective local and systemic immune defenses in the elderly population $[13,14]$.

The development of strategies aimed at counterbalancing the immune frailty in the elderly is a major challenge for $21^{\text {st }}$ century medicine. Nutritional supplementation, including probiotics, in this population may help maintain immune function either by direct interaction with the host immune system or indirectly by re-equilibrating the gut microbiota [15-17].

Probiotics have been defined as 'Live microorganisms which when administered in adequate amounts confer a health benefit on the host' [18]. Lactobacillus and Bifidobacterium are the most commonly used bacterial probiotics. Fermented milk or dairy products containing Lactobacillus have shown effects on duration or frequency of respiratory and gastrointestinal infections [19-21] and reduced the risk of the common cold in healthy elderly subjects [22]. Mañé et al. [23] showed significant trends in reducing infection incidence and mortality due to pneumonia in institutionalized elderly subjects treated with two Lactobacillus plantarum strains. Some trials showed that Lactobacillus and Bifidobacterium probiotics could increase influenza vaccination immune responses in the elderly [24-27].

Endospore formers such as Bacillus species are interesting because their spores resist the acid barrier of the stomach and are stable for long periods in commercial food products [28]. Bacilli, considered as gut commensals, have been used as probiotics for prophylaxis of human gastrointestinal disorders, to prevent recurrent respiratory infections or as an adjunct to antibiotic use [29-34].

Probiotics have been suggested to protect against infectious diseases by several strain-dependant mechanisms $[35,36]$ including secretion of anti-pathogen substances, competitive exclusion of pathogens, maintenance of mucosal integrity and stimulation of systemic or mucosal immune responses [35-39]. Bacillus species have been shown to produce antimicrobial substances $[40,41]$, to enhance epithelial gut barrier functions [42, 43] and stimulate cytokine [43-45] and SIgA in humans [46].

In this study we evaluated the beneficial effect of Bacillus subtilis CU1 administration in an elderly population. This probiotic displays immunostimulating properties and antagonizes gastrointestinal pathogen infection by producing antimicrobial substances such as amicoumacins (Racedo SM \& Urdaci MC, unpublished observations). This randomized, double-blind placebo-controlled study investigated the effect of probiotic strain $B$. subtilis CU1 intake on resistance to common infectious disease (CID), notably by measuring mean cumulative number of days with CID in healthy free-living seniors (individuals over 60 years old). As secondary endpoints, the study examined the effect of B. subtilis CU1 intake on the stimulation of the mucosal and systemic immune response by measuring intestinal and salivary SIgA levels and serum cytokine levels, respectively, in a subset of 44 subjects.

\section{Results}

\section{Subject characteristics}

One hundred thirty two (132) subjects were screened for study eligibility, and 100 were randomized to the probiotic group $(N=50)$ or to the placebo group $(N=50)$ (Fig. 1). All enrolled subjects completed the study without major deviation.

The baseline characteristics for the population are presented in Table 1. The data from the initial clinical examination were normal for all volunteers. Mean age observed in the probiotic group (63.3 (2.8) years of age) and placebo group (63.0 (2.4) years of age) were consistent with inclusion criteria. The influenza vaccination rates in the subjects, seasonal influenza and influenza $\mathrm{A}$, from the beginning of the influenza vaccination season (September) were respectively $16.0 \%$ and $8.0 \%$ in probiotic group and $14.0 \%$ and $12.0 \%$ in placebo group. A good mean compliance was observed ( $>99 \%$ in both groups).

\section{Clinical outcomes on the whole study population}

Considering the whole study population $(N=100)$, the mean number of days with CID symptoms over the 4month study period was $5.1(7.0) \mathrm{d}$ in the probiotic group and $6.6(7.3) \mathrm{d}$ in the placebo group $(P=0.2015)$ (Table 2). The percentage of subjects reporting at least one CID episode during the study was $58.0 \%$ in the probiotic group $(N=29 / 50)$ and $66.0 \%$ in the placebo group $(N=33 / 50)(P=0.4106)$. The risk to report an

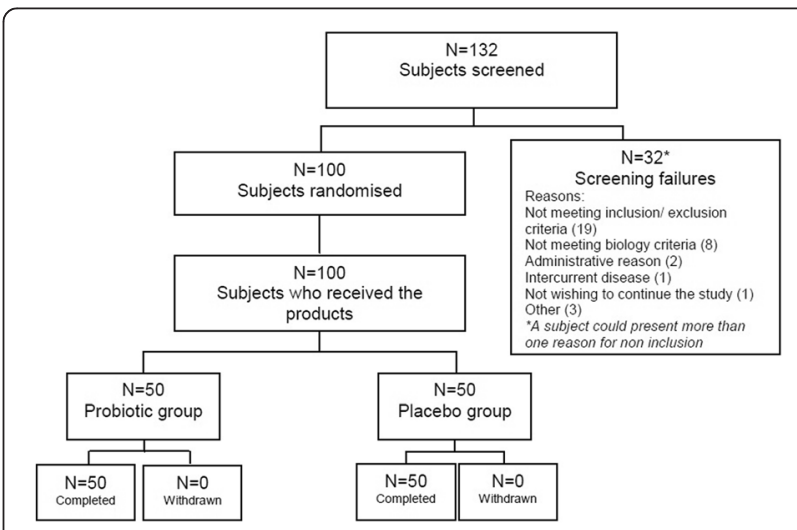

Fig. 1 Flow chart of subjects 
Table 1 Baseline subject characteristics of the whole population $(N=100)$, by product group

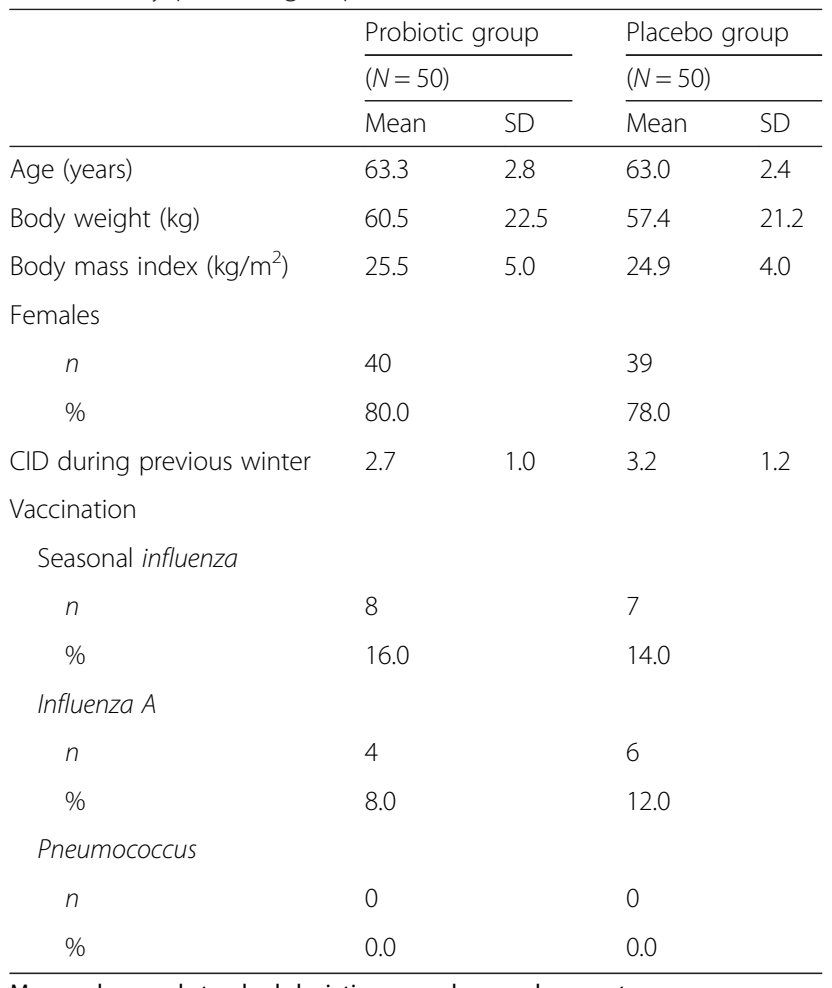

Mean values and standard deviations; numbers and percentages infectious episode in the probiotic group was $12 \%$ lower than in the placebo group (Relative Risk $=0.88$ $[1.20 ; 0.65])$. There was no statistically significant difference between the probiotic and the placebo groups in mean duration, intensity, and frequency of CID during the observation period $(P=0.2361, P=0.7400$, and $P=$ 0.3290 respectively).

\section{Clinical outcomes on the subset of 44 subjects (post-hoc analysis)}

Considering the subset of the 44 subjects, the mean number of days with CID symptoms was 4.5 (7.3) days in the probiotic group and 7.3 (8.2) days in the placebo group $(P=0.1101)$ (Table 2$)$. In this subset, the percentage of subjects reporting at least one infectious episode during the study was $50.0 \%(N=11 / 22)$ in the probiotic group and $72.7 \%(N=16 / 22)$ in the placebo group $(P=0.1260)$. The risk to report an infectious episode was $31 \%$ lower in probiotic group than in placebo group (Relative Risk $=0.69$ [1.12;0.42]). There was no difference in mean duration, intensity and frequency of CID during the observation period between the probiotic and placebo groups $(P=0.2361, P=0.7400$, and $P=0.1117$ respectively). In the same subset $(N=44)$, the frequency of respiratory infections was significantly lower in the probiotic group compared to the placebo group $(P=0.0323)$ : a mean number of $0.6(0.7)$ respiratory infections was observed in the probiotic group vs. $1.1(0.9)$ in the placebo group. The mean number of days with respiratory CID

Table 2 Effect of probiotic (B. subtilis CU1) and placebo consumption on clinical outcomes of infectious diseases

\begin{tabular}{|c|c|c|c|c|c|c|c|c|c|c|}
\hline & \multicolumn{5}{|c|}{ Whole population $(N=100)$} & \multicolumn{5}{|c|}{ Subset of population $(N=44)$} \\
\hline & \multicolumn{2}{|c|}{$\begin{array}{l}\text { Probiotic group } \\
(N=50)\end{array}$} & \multicolumn{2}{|c|}{$\begin{array}{l}\text { Placebo group } \\
(N=50)\end{array}$} & \multirow[t]{2}{*}{$P$} & \multicolumn{2}{|c|}{$\begin{array}{l}\text { Probiotic group } \\
(N=22)\end{array}$} & \multicolumn{2}{|c|}{$\begin{array}{l}\text { Placebo group } \\
(N=22)\end{array}$} & \multirow[t]{2}{*}{$P$} \\
\hline & Mean & SD & Mean & SD & & Mean & SD & Mean & SD & \\
\hline Mean number of days with CID & 5.1 & 7.0 & 6.6 & 7.3 & $0.2015^{\mathrm{a}}$ & 4.5 & 7.3 & 7.3 & 8.2 & $0.1101^{\mathrm{a}}$ \\
\hline Mean duration of CID (d) & 5.0 & 4.6 & 5.3 & 4.1 & $0.2361^{\mathrm{a}}$ & 5.8 & 5.6 & 5.7 & 4.1 & $0.2361^{\mathrm{a}}$ \\
\hline Mean intensity of CID & 8.1 & 5.0 & 7.6 & 4.4 & $0.7400^{\mathrm{a}}$ & 9.0 & 6.2 & 8.8 & 5.3 & $0.7400^{\mathrm{a}}$ \\
\hline CID frequency & 1.0 & 1.2 & 1.2 & 1.2 & $0.3290^{\mathrm{a}}$ & 0.8 & 1.0 & 1.3 & 1.2 & $0.1117^{\mathrm{a}}$ \\
\hline Subjects with at least one CID & & & & & $0.4106^{b}$ & & & & & $0.1260^{b}$ \\
\hline$n$ & 29 & & 33 & & & 11 & & 16 & & \\
\hline$\%$ & $58 \cdot 0$ & & $66 \cdot 0$ & & & $50 \cdot 0$ & & $72 \cdot 7$ & & \\
\hline Mean number of days with $\mathrm{Rl}$ & 4.4 & 6.9 & 6.2 & 7.2 & $0.1027^{a}$ & 3.7 & 6.9 & 6.6 & 7.9 & $0.0818^{\mathrm{a}}$ \\
\hline Mean duration of RI (d) & 5.9 & 5.0 & 5.6 & 4.2 & $0.9043^{\mathrm{a}}$ & 6.8 & 6.3 & 6.1 & 4.3 & $0.9325^{\mathrm{a}}$ \\
\hline Mean intensity of Rl & 9.3 & 5.3 & 7.8 & 4.6 & $0.1428^{a}$ & 11.1 & 6.3 & 9.3 & 5.6 & $0.3473^{\mathrm{a}}$ \\
\hline Rl frequency & 0.7 & 0.9 & 1.1 & 1.2 & $0.1181^{\mathrm{a}}$ & 0.6 & 0.7 & 1.1 & 0.9 & $0.0323^{\mathrm{a}}$ \\
\hline Subjects with at least one Rl & & & & & $0.1609^{b}$ & & & & & $0.0701^{b}$ \\
\hline$n$ & 24 & & 31 & & & 10 & & 16 & & \\
\hline$\%$ & 48.0 & & 62.0 & & & 45.5 & & 72.7 & & \\
\hline
\end{tabular}

Data are presented for the whole population $(N=100)$ and the subset of population with biology analysis $(N=44)$. (Mean values and standard deviations; numbers and percentages)

Statistical differences were evaluated using Wilcoxon-Mann-Whitney's test or Savage's test according to the asymmetry of data $\left({ }^{a}\right)$, or logistic regression model $\left({ }^{b}\right)$ 
symptoms was $3.7(6.9)$ in the probiotic group and 6.6 (7.9) in the placebo group $(P=0.0818)$.

\section{Immunological parameters (subset of 44 subjects) Mucosal response}

Fecal and salivary SIgA response. SIgA is widely used as marker of mucosal immunity in clinical studies [47]. Remarkably, we observed a significantly higher concentration of SIgA in stools in the probiotic group compared to the placebo group after $10 \mathrm{~d}$ of product consumption (probiotic group: 2062.6 (1161.8) $\mu \mathrm{g} / \mathrm{ml}$; placebo group: 1249.5 (863.8) $\mu \mathrm{g} / \mathrm{ml} ; P=0.0038$ ) (Fig. 2). The increased SIgA levels were still observed at the end of consumption and $18 \mathrm{~d}$ after the end of B. subtilis CU1 consumption (probiotic group: 2424.4 (1252.3) $\mathrm{\mu g} / \mathrm{ml}$; placebo group: 1297.1 (953.7) $\mu \mathrm{g} / \mathrm{ml} ; P=0.0032$ ). Furthermore, fecal SIgA concentrations significantly increased between pre- and post-supplementation with B. subtilis CU1 after 10 days of probiotic consumption $(P=0.0012)$. Elevated levels persisted $18 \mathrm{~d}$ after the last probiotic consumption $(P=0.0008)$. SIgA concentrations in stools were not statistically affected by placebo consumption. In addition, a significantly higher concentrations of salivary SIgA were observed in the probiotic group compared to the placebo group at the end of consumption and $18 \mathrm{~d}$ after the end of B. subtilis CU1 consumption (probiotic group: 940.4 (446.0) $\mu \mathrm{g} / \mathrm{mL}$; placebo group: 650.1 (343.5) $\mu \mathrm{g} / \mathrm{mL} ; P=0.0219$ ) (Fig. 3).

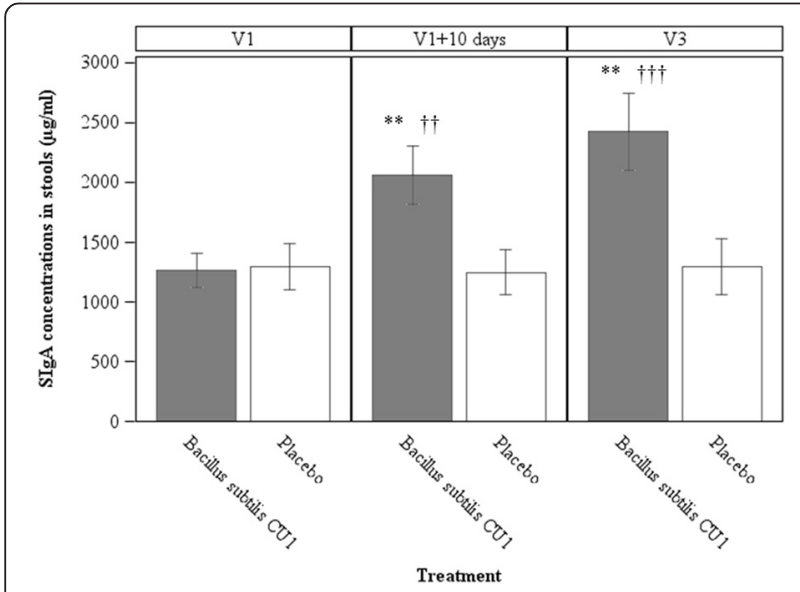

Fig. 2 Concentrations of secretory IgA in stools. Fecal SlgA concentrations were assessed in subjects from the subset of population $(N=44)$, at baseline $(\mathrm{V} 1)$, after 10 days of consumption of study products $(\mathrm{V} 1+10 \mathrm{~d})$ and at the end of the study (V3). Values are means, with standard error of means represented by vertical bars. Fecal SIgA concentrations were significantly higher in the probiotic group compared to the placebo group (**P $<0.01$ ), and significantly increased in the probiotic group during the study $(†+P<0.01$, + †† $P<0.001)$

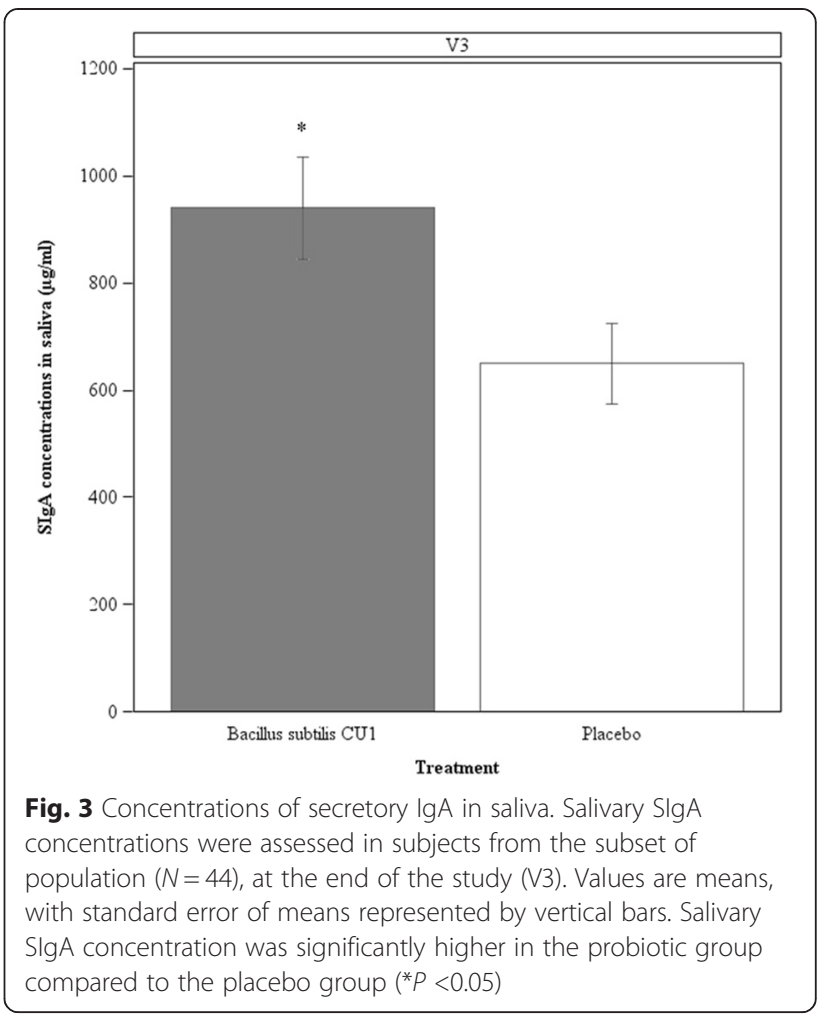

\section{Systemic response}

Blood IFN response (Fig. 4). No statistically significant difference in IFN-gamma concentrations were observed between groups, after $10 \mathrm{~d}$ of probiotic consumption $(\mathrm{V} 1+10 \mathrm{~d}$ ) (probiotic group: 9.7 (8.1) pg/mL; placebo group: 31.8 (92.4) pg/mL; $P=0.0981)$. However, IFNgamma concentrations significantly increased in the probiotic group from first pre- to post- supplementation, after $10 \mathrm{~d}$ of probiotic consumption (probiotic group at V1: 6.9 (5.0) $\mathrm{pg} / \mathrm{mL} ; P=0.0090$ ), while no significant change was observed in the placebo group. No statistically significant differences in the plasma concentrations of cytokines (IL-1beta, IL-4, IL-6, IL-8, IL-10, IL-12p70, IgA, and TNF-alpha) were measured between the probiotic and the placebo groups from pre- to post- supplementation.

\section{Numeration of $B$. subtilis in the stools (subset of 44 subjects)}

An increase in Bacillus spore concentrations were observed in stools of subjects from the probiotic group but not in the placebo group (Table 3). Molecular typing using the OPL12 primer showed the presence of the B. subtilis CU1 strain in stools as opposed to the placebo group and demonstrates the viability of the probiotic strain.

\section{Stool cytotoxicity (subset of $\mathbf{4 4}$ subjects)}

No statistically significant difference was measured in the cytotoxicity levels in stools between the 


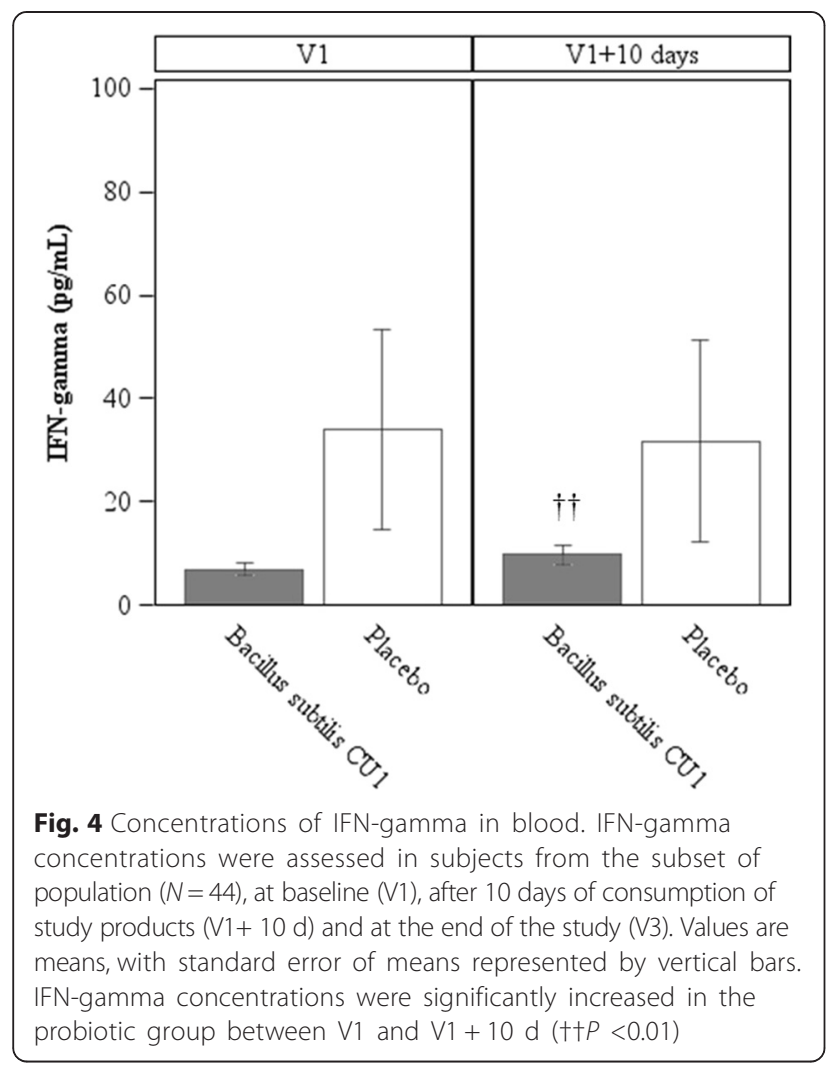

probiotic group (94.25\% (34.46) of viability) and placebo group (93.98\% (31.06) of viability), after 10 $\mathrm{d}$ of product consumption $(P=0.6328)$. These data confirm the absence of stool cytotoxicity induced by B. subtilis CU1.

\section{Safety (whole study population)}

Investigators reported 108 adverse events in the probiotic group and 85 in the placebo group $(P=0.8369)$. There were no abnormal values of biological parameters at the end of the study, and no clinically significant variation was observed during the study, on renal and hepatic functions.

Table 3 Bacterial counts of Bacillus spores in the stools of the subset population $(N=44)$

\begin{tabular}{lllll}
\hline & \multicolumn{3}{l}{ Whole population $(N=100)$} & \\
\cline { 2 - 5 } & \multicolumn{1}{l}{ Mrobiotic group $(N=22)$} & \multicolumn{2}{l}{ Placebo group $(N=22)$} \\
\hline \multirow{2}{*}{ V1 } & $2.5 .10^{3}$ & $3.0 .10^{3}$ & $2.5 .10^{3}$ & $5.4 .10^{3}$ \\
V1 +10 days & $1.9 .10^{7}$ & $1.1 .10^{7}$ & $2.3 .10^{3}$ & $5.1 .10^{3}$ \\
V3 & $7.5 .10^{3}$ & $1.5 .10^{4}$ & $3.0 .10^{3}$ & $4.4 .10^{3}$ \\
\hline
\end{tabular}

Mean values and standard deviations

\section{Discussion}

The current controlled study was designed to evaluate the effect of probiotic strain B. subtilis CU1 consumption $\left(2.10^{9}\right.$ spores/d) on immune system stimulation and resistance to respiratory and gastrointestinal CID in healthy free-living seniors with known past histories of CID during the winter period. The demographic characteristic of the volunteers, the duration of study and the compliance to product consumption were similar for probiotic and placebo groups. The probiotic product was safe and well tolerated. An increase in B. subtilis CU1 concentration was observed in stools after intake of the probiotic product, which suggests survival of the strain in the gastrointestinal tract and is consistent with high compliance of study assessed by product consumption. The probiotic did not significantly affect CID in the whole population $(N=100)$. In the subset of 44 subjects, and as planned in the protocol, biological explorations were performed. These analyses showed that B. subtilis CU1 significantly increased the levels of SIgA in stools $(P=0.0032)$ and saliva $(P=0.0219)$ in comparison to placebo and induced significantly higher levels of serum IFN-gamma $(P=0.0090)$. Furthermore, a post-hoc analysis in this subset of subjects showed a statistically lower frequency of respiratory infections in the probiotic group compared to the placebo group $(P=0.0323)$.

We readily acknowledge several limitations to our study. Except for respiratory infections in the subset of 44 subjects, the clinical efficacy of oral administration of probiotic $B$. subtilis CU1 did not reach statistical significance. Consequently the study hypothesis was not reached, i.e., to observe a difference of $3 \mathrm{~d}$ in CID episodes between the two groups. However the statistical power of our study was lower than expected and B. subtilis supplementation tended to decrease the mean number of days with respiratory CID symptoms compared to the placebo group in the subset of 44 subjects (post-hoc analysis). In addition, $B$. subtilis CU1 supplementation significantly reduced the frequency of respiratory infections in this subset of population $(P=0.0323)$. This subgroup was originally planned in the protocol only for biological analysis and the clinical efficacy observed in this subset, while not confirmed in the whole population, might be explained either by chance only or by the higher infection rates at the beginning of the clinical study (i.e., beginning of winter season, which is likely to correspond to the highest CID exposure period).

\section{B. subtilis CU1 stimulates systemic immune response}

In the present study, we observed that supplementation with $B$. subtilis CU1 stimulated systemic immune response in seniors by significantly increasing serum IFNgamma in the probiotic group following first B. subtilis supplementation. Concentrations of other measured 
serum cytokines and serum IgA were not significantly modified. These results are in accordance with previous mouse studies using B. subtilis CU1 (Racedo SM \& Urdaci MC, unpublished observations). Huang et al. [48] also found that Bacillus strains could stimulate systemic and intestinal IFN-gamma production in mice. This ProTh1 cytokine plays a role in the host defense against several infectious diseases, including viral infection and has a variety of immune functions such as stimulation of macrophages and natural killer cells $[49,50]$. Different studies have emphasized the importance of IFN-gamma production for the protective effect of probiotics against influenza infection $[51,52]$. Further investigations in $B$. subtilis CU1's capability in increasing serum IFN-gamma levels and the strengthening of the systemic anti-viral and anti-bacterial immune defenses in the elderly population would be interesting.

\section{B. subtilis CU1 enhances intestinal and respiratory mucosal immune responses}

An important finding of the present study was that, compared to placebo, the oral intake of B. subtilis CU1 resulted in higher SIgA production in the healthy seniors. Ten days of probiotic intake were sufficient to increase stool SIgA levels $65 \%$ in treated seniors compared to placebo. Moreover, an increased level of $87 \%$ was maintained at least 18 days after the last probiotic administration. Previous controlled clinical trials have shown that the intake of probiotic bacteria (mainly Lactobacillus and Bifidobacterium) stimulates mucosal immune systems by enhancing fecal IgA [53, 54]. Kabeerdoss et al. [54] observed an increase of fecal IgA during probiotic intake with a subsequent decrease after cessation of administration of the probiotic.

We assessed SIgA concentrations in saliva at the end of the 18-d follow up period. B. subtilis CU1 intake produced a $45 \%$ increase in SIgA relative to placebo group. Since B. subtilis CU1 had been shown to increase IgA producing B cells in Peyer's patches in mice (Racedo SM \& Urdaci $\mathrm{MC}$, unpublished observations), one can postulate that $B$. subtilis $\mathrm{CU} 1$ consumption strengthens the generation of $\alpha 4 \beta 7^{+} \operatorname{IgA}{ }^{+} B$ cells in the Peyer's patches of the small intestine of elderly subjects. The homing of these IgA producing B cells to the intestinal mucosa and the salivary glands [55] most probably accounts for the high SIgA levels measured in the feces and saliva of the probiotic group. In the elderly, only one previous study has shown that oral administration of heat-killed Lactobacillus pentosus $b 240$ produced an increase in salivary IgA secretion [16]. Importantly, it has been shown, in mice, that $50 \%$ increase production of intestinal SIgA to a bacterial toxin significantly increased the vaccineinduced protection directed against the toxin [56]. Additionally, it has also been shown that a $20 \%$ increase in production of total SIgA in saliva is associated with a decrease in the incidence of colds and flu-like symptoms in humans [57, 58]. Therefore, increased SIgA levels of $87 \%$ and $45 \%$ in faeces and saliva respectively are most probably of physiological significance in ameliorating the health status of seniors receiving B. subtilis CU1.

Taken together, these findings show the utility of oral administration of probiotic B. subtilis CU1 to increase mucosal immune responses. The increased SIgA levels in the intestine and saliva might contribute to strengthening the mucosal anti-viral and anti-bacterial immune defenses of the elderly population. It has to be noted that secretion of salivary SIgA has been shown to be impaired by stress such as academic stress or intensive physical exercise $[59,60]$. Therefore interesting future work would be to investigate whether $B$. subtilis CU1 stimulation of mucosal immune system might be beneficial in the general population, notably in a population under stress.

King et al. [61] recently published a meta-analysis and systematic review showing that Lactobacillus spp. and Bifidobacterium spp. strains brought by food products or supplements significantly lowered the number of days of acute respiratory infections in a healthy population of children and adults and shortened acute respiratory infectious periods. There are only few studies in the elderly and the present one is the first to indicate a trend toward a reduction of CID by a B. subtilis strain in this population. Additional larger clinical trials have to be conducted to confirm these clinical outcomes.

\section{Conclusions}

Despite the absence of significant results on CID in the whole population, the present study showed that consumption of B. subtilis CU1 significantly increased intestinal and salivary SIgA and serum IFN-gamma levels in a subset senior population. It suggests that daily B. subtilis CU1 supplementation during the winter months may be a safe effective way to stimulate systemic and mucosal immune responses of the elderly. However, no firm conclusion can be made about the effect of B. subtilis CU1 supplementation on CID. Additional larger clinical trials have to be conducted to confirm these clinical outcomes.

\section{Methods}

\section{Ethics, consent and permissions}

The study was approved by the West IV Ethics Committee for Human Research and the French Health Products Safety Agency (AFSSAPS), France and was performed in accordance with the principles of the Declaration of Helsinski, of Good Clinical Practice (Directive ICH E-6, 24 November 2006), and current French regulations (Code de Santé Publique, Titre II du livre Premier). All participants 
had given their written informed consent before inclusion in the study.

\section{Study subjects}

One hundred (100) healthy free-living adults between 60 and 74 years of age, without any known congenital or immune defects, severe chronic disease or allergies and reporting at least two CID episodes during the previous winter period were recruited. Subjects were not included if any of the following criteria applied: chronic respiratory insufficiency, cardiac insufficiency, cancer (chemotherapy, radiotherapy), unstabilized chronic disease (severe renal or hepatic insufficiency, etc.), or any chronic severe affection likely to interfere with evaluation of the study parameters. For the inclusion, subjects were not allowed to take any drug potentially known to interfere with the evaluation of the study parameters, including corticoids and immunosuppressive drugs. Consumption of dietary supplements was forbidden in the last 2 months before inclusion, as well as regular consumption of probiotic products 1 month before the start of the study.

\section{Study design}

The study was a monocentric, randomized, double-blind, placebo-controlled, parallel arms trial. Subjects were randomly allocated to the probiotic group or to the control group.

The study lasted 16 weeks and consisted of four consumption periods of $10 \mathrm{~d}$ each, followed by $18 \mathrm{~d}$ without consumption of the study products (break period).

At the selection visit, 1 or 2 weeks before initiation of the study, volunteers underwent a clinical examination and blood was taken from volunteers to assess safety parameters and measure of biological inclusion parameters. The investigators checked for inclusion criteria and recorded the subject's demographic characteristics. Eligible volunteers were randomly allocated by the investigator to the probiotic or the placebo group on Visit 1 (V1) of the study, according to the randomization list. Randomization was done without stratification using $\mathrm{SAS}^{\bullet}$ software version 9.1.3 Service Pack 4 (SAS Institute Inc., Cary, NC, USA). The randomization list was prepared before the beginning of the study by a person not related to the clinical phase, the data management or statistics. In addition, it was prepared and stored confidentially. The unblinding envelopes were concealed from the person responsible for randomization. During the study, four visits were planned: V1 (inclusion visit, beginning of the $1^{\text {st }}$ product consumption period), $\mathrm{V} 1+10 \mathrm{~d}$ (follow-up visit, 10 days after V1, end of the $1^{\text {st }}$ product consumption period), V2 (follow-up visit, 2 months after V1) and V3 (end-of-study visit, 4 months after V1) (Fig. 5).

The trial was conducted during the winter season 2010-2011, in the Nantes area, France.

\section{Study products}

Study products were presented in the form of food supplements. The probiotic product consisted of B. subtilis CU1 mixed with excipients (maltodextrin DE14, dicalcic phosphate, magnesium stearate, colloidal silica). Each probiotic capsule contained $2.10^{9}$ spores of B. subtilis CU1 (LESAFFRE, Marcq en Baroeul, France). The probiotic preparation contains $95 \%$ of $B$. subtilis spores and $5 \%$ of vegetative cells. Due to spore stability over time, the probiotic counts were the same at beginning and at the end of study. The placebo capsule contained only the excipient mix. Placebo products were indistinguishable from the probiotic product in appearance, smell and taste.

During the four 10-d product consumption periods, the subjects were instructed to consume daily one capsule of the study product, in the morning (40 min before breakfast). Otherwise, subjects were asked not to modify their food habits and they were prohibited from taking any dietary supplement or food product containing probiotics during the study.

\section{Study endpoints}

The primary endpoint was a between products comparison of the mean cumulative number of days with CID (upper and lower respiratory tract infections, gastrointestinal tract infections) during the 4 months of study in the whole population $(N=100)$. In addition, some clinical endpoints were analysed in the whole population, and biological endpoints in the subset of the first

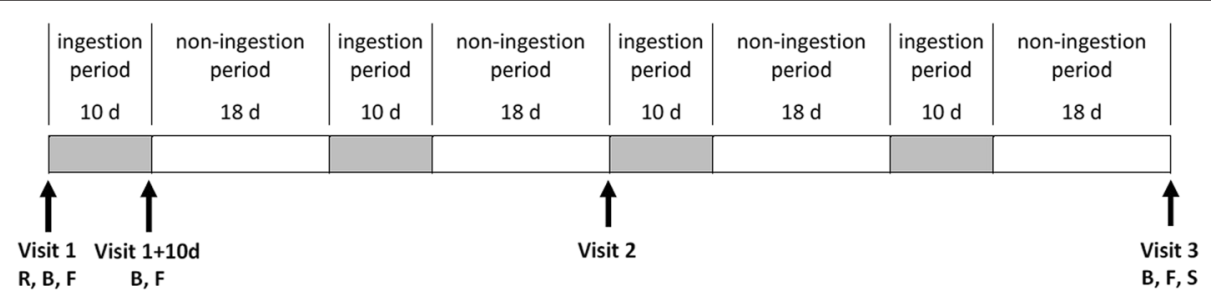

Fig. 5 Study design. R indicates randomization of the 100 subjects. Blood samples (B), fecal samples (F) and salivary samples (S) concerned a subset of 44 subjects 
44 subjects (half in the B. subtilis group, half in the placebo group).

Clinical endpoints included the mean duration of CID, the intensity of CID, the frequency of CID, and the percentage of subjects with at least one CID $(N=100)$. Biological endpoints included blood immunological marker concentrations (IL-1beta, IL-4, IL-6, IL-8, IL-10, IL-12p70, TNF-alpha, IgA, IFN-gamma, at V1 and V1 + $10 \mathrm{~d}$ ), salivary secretory IgA concentration (at V3), and fecal secretory IgA concentration (at V1, V1 $+10 \mathrm{~d}$ and V3) $(N=44)$. At last, the presence of B. subtilis in stools and the cytotoxicity of stools were analysed in the subset population $(N=44)$.

\section{Common infectious disease symptoms}

During the 4 months of study, subjects were instructed to track any CID symptoms they had in a diary. The items detailed in this diary were: symptoms of gastrointestinal and upper/lower respiratory tract infections (cough, hoarseness, sore throat, itchy throat, rhinorrhea, sneezing, nasal obstruction, conjunctivitis, fatigue, headache, myalgia, nausea), body temperature, vomiting, and diarrhoea.

The intensity of each symptom of gastrointestinal and upper/lower respiratory tract infections was rated on a 4-point scale (from 0: no symptom to 3: severe symptom) whereas fever (i.e., body temperature increased from at least one degree higher compared to basal temperature), vomiting and diarrhoea (i.e., more than 3 liquid stools per day) were rated on dichotomous scales $(0=$ absence; $3=$ experience of the sign). All symptoms were reviewed by the investigator who determined if they complied with the diagnosis of a CID or not. When a CID was diagnosed, a symptomatic score was calculated on a daily basis, taking into account CID symptoms, fever, vomiting, and diarrhoea. This score rates from 0 to 45 arbitrary units.

For analysis of the mean number of days with CID and the frequency of CID, all subjects were considered and "0" was applied to subjects without CID.

\section{Sample collection}

Fasting blood samples and stool samples were collected at V1, V1 $+10 \mathrm{~d}$ and V3 among the first 44 randomized subjects $(N=22$ in probiotic group, $N=22$ in placebo group), which corresponded to the first twenty-two subjects enrolled in each group. The randomized repartition of the subjects was ensured by the randomization list. Blood was centrifuged for $10 \mathrm{~min}$ at $1,000 \mathrm{x}$ g at $4{ }^{\circ} \mathrm{C}$ to separate serum. An aliquot of the serum was used for IgA determination and a second aliquot was collected for cytokine analysis. Additionally, saliva samples were collected at V3 in the same subset. Biological samples, serum, stools and saliva were stored frozen at $-80{ }^{\circ} \mathrm{C}$ until analysis.

\section{Serum, stools and saliva Immunoglobulin A (IgA) quantification}

Serum IgA concentration was measured by Elisa (enzyme-linked immunosorbent assay) according to the manufacturer's instructions (Hitachi 911, Roche, Basel, Switzerland). SIgA in stools and saliva were measured by Elisa (Immuchron AG, Heppenheim, Germany) according to the manufacturer's instructions.

\section{Serum cytokine quantification}

Interleukins (IL-1beta, IL-6, IL-8, IL-10, IL-12p70), Tumor Necrosis Factor alpha (TNF-alpha) and Interferon gamma (IFN-gamma) were measured using Human Th1/Th2 11plex FlowCytomix immunoassays (eBioscience, Inc) on the BD Accuri ${ }^{\mathrm{m}} \mathrm{C}$. Flowcytometer (BD Bioscience) and ELISA (Ready-SET-Go ${ }^{\circ}$ eBioscience, Inc.). Furthermore, human Interferon beta (IFN-beta) was analyzed by Elisa (R\&D Systems, Inc.). All assays were performed according to the manufacturer's instructions.

\section{Bacillus spores counts in stools and CU1 strain identification}

Stools samples ( 2 g) were placed in Stomacher 400 classic bags, diluted with $18 \mathrm{ml}$ of sterile physiological saline water and homogenized for $2 \mathrm{~min}$. Ten $\mathrm{ml}$ of dilutions were heated $\left(80{ }^{\circ} \mathrm{C}\right.$ for $\left.10 \mathrm{~min}\right)$ in order to kill bacterial vegetative cells. Samples were serially diluted $1: 10$ in sterile saline and plated on Mueller- Hinton Agar plates (Difco BD Laboratory, Franklin Lakes, USA) for $24 \mathrm{~h}$ at $37^{\circ} \mathrm{C}$ for spores counts.

In order to identify CU1 colonies in plates, a molecular typing method RAPD (Randomly Amplified Polymorphic DNA) was used. Different types of colonies from every fecal sample were analyzed in triplicate using the OPL12 primer that generates a specific profile for the CU1 strain [62].

\section{Assessment of stool cytotoxicity}

Stool samples $(1 \mathrm{~g})$ were diluted in $5 \mathrm{ml}$ of Dulbecco's modified Eagle's minimum essential medium (DMEM). After homogenization, samples were centrifuged at $10000 \mathrm{~g}$ for $10 \mathrm{~min}$, then filtered through a $0.2 \mu \mathrm{m}$ membrane filter and diluted 1/20 (volume/volume (v/v)) in DMEM media. Stool cytotoxicity was evaluated by quantifying Vero cell detachment.

Vero cells were grown in DMEM containing $25 \mathrm{mM}$ glucose (Sigma-Aldrich), supplemented with $10 \%(\mathrm{v} / \mathrm{v})$ heat-inactivated fetal calf serum (Gibco), $1 \%(\mathrm{v} / \mathrm{v})$ nonessential amino acids (Sigma), penicillin (100 UI/ml), streptomycin $(100 \mu \mathrm{g} / \mathrm{ml})$, gentamicin $(50 \mu \mathrm{g} / \mathrm{ml})$ (Sigma). For maintenance purposes, cells were passed every $3 \mathrm{~d}$, using Accutase Solution (Sigma). Monolayers were prepared in 48-well tissue culture plates (Greiner Bio One, Germany) by seeding $5.10^{4}$ cells per well. Experiments and cell maintenance were carried out at $37{ }^{\circ} \mathrm{C}$ in a $5 \%$ 
$\mathrm{CO}_{2}-95 \%$ air atmosphere. Fully confluent cells (3-4 d in culture) were used throughout.

Briefly, confluent cells were co-incubated with the different stool samples at $37{ }^{\circ} \mathrm{C}$ for $2 \mathrm{~h}$ and then cells were washed with phosphate-buffered saline (PBS), fixed for 1 min with $2 \%(\mathrm{v} / \mathrm{v})$ formaldehyde in PBS, washed again in PBS and stained with $500 \mu \mathrm{l}$ of crystal violet solution $(0.13 \%$ crystal violet, $5 \%$ ethanol, and $2 \%$ formaldehyde in $\mathrm{PBS} \mathrm{w} / \mathrm{v} / \mathrm{v}$ ) for $20 \mathrm{~min}$ at room temperature. After being exhaustively washed with PBS to remove stain excess, samples were treated for $1 \mathrm{~h}$ with freshly prepared $50 \%$ ethanol in PBS (v/v) at room temperature. Absorbance was measured at $650 \mathrm{~nm}$ in a Thermo Max Microplate spectrophotometer reader. Percentage of attached cells was calculated as: $100 \times(\boldsymbol{A} / \mathbf{A c})$, where $\mathbf{A}$ is the absorbance of treated cells and Ac is the absorbance of untreated control cells. As positive control a diluted supernatant of Clostridium difficile VPI 10463 was used.

\section{Safety}

Adverse events were collected during the study by investigators and reported in the case report forms of each subject. The investigators had also to evaluate imputability of any adverse event to the study products.

\section{Statistical analysis}

Based on previous pilot clinical studies, sample size was calculated to detect an intergroup difference of $3 \mathrm{~d}$ in CID episodes (with Standard Deviation (SD): $5 \mathrm{~d}$ ), using a twotailed $t$-test at the significance level of $0 \cdot 05$. Forty-eight subjects were required in each group to provide $80 \%$ statistical power. To account for potential drop-outs, it was planned to include fifty subjects in each group.

Data were analysed using $\mathrm{SAS}^{\oplus}$ software version 9.1.3 Service Pack 4 (SAS Institute Inc., Cary, NC, USA). Results are expressed as Mean (SD). Significance was set at $P<0.05$.

The mean number of days with CID and other clinical outcomes (mean duration, intensity, and frequency of CID) were compared between groups using the Wilcoxon-Mann-Whitney's test or Savage's test (according to the asymmetry of data). The percentage of subjects with at least one CID was compared betweengroup using a logistic regression model. Immunological variables with a normal distribution (plasma, salivary and fecal IgA, IL-6, IL-8, IL-10, IL-12, and stool cytotoxicity) were compared using Student's $t$-test for between-group analysis and Student's paired $t$-test for within-group analysis. For criteria which do not respect normal distribution (IFN-gamma, TNF-alpha, IL-1 and IL-4), a Wilcoxon-Mann-Whitney's test was applied for between group analysis, and completed with Savage's test for IL-1 and IL-4 due to dissymmetry of these biological parameters. Within-group analysis was performed using Wilcoxon's paired test. The number of subjects with at least one side-effect in each group (probiotic and placebo groups) was compared using Chi-square test.

Following this primary analysis, some post-hoc analyses were performed. The first analysed the clinical outcomes reported in the subset of 44 subjects (number of days with CID, mean duration of CID, intensity of CID, frequency of CID, and percentage of subjects with at least one CID). The second post-hoc analysis applied on the clinical outcomes in subjects who reported at least one symptom of upper/lower respiratory tract infections, whatever this symptom was or not associated to a symptom of gastrointestinal infection. This latter analysis was performed in the whole population of 100 subjects and in the subset of 44 subjects. The statistical models were identical to the ones applied for the primary analysis.

\section{Abbreviations}

CID: Common Infectious Disease; DMEM: Dulbecco's Modified Eagle's Minimum Essential Medium; PBS: Phosphate-Buffered Saline; SD: Standard Deviation; v/v: volume/volume; w/v/v: weight/volume/volume.

\section{Competing interests}

The clinical study was performed by BIOFORTIS, a Mérieux NutriSciences Company, 3 route de la Chatterie, Saint-Herblain, France.

This study was performed as part of the research project Probisis partially financed by the French Government 3rd FUI research program, and supported by the Research cluster Prod'Innov of the region Aquitaine and LESAFFRE.

P. Marteau has received honoraria for consultancy or lectures from: Biocodex, Danone, Nestlé, Merck Médication Familiale, Mayoli Spindler.

\section{Authors' contributions}

All authors participated in the design of the trial, data interpretation and preparation of the manuscript. ML and PJ conducted the project and supervised manufacturing of the product. SR, GR, MU and Biofortis undertook biological analysis. CM performed the analysis and interpretation of statistical data, MC was involved in the study conception and design, $\mathrm{BH}$ contributed to the study conception and design. All authors read and approved the final manuscript.

\section{Authors' information}

M. Lefevre holds a full time position with SAFISIS, a LESAFFRE Group subsidiary.

P. Justen holds a full time position with LESAFFRE HUMAN CARE, a Business Unit of LESAFFRE Group.

\section{Acknowledgements}

The authors would like to thank subjects for their interest, time, and compliance with dietary supplementation. They thank Anne Marie Elie for carrying fecal analyses and Dr. Dominique Velin, Service of Gastroenterology and Hepatology, Department of Medicine, Lausanne University Hospital, Lausanne, Switzerland, for his expert assistance.

Writing support was provided by Gunnard K Jacobson of Lesaffre Yeast Corporation.

\section{Author details}

'Lesaffre Human Care, Lesaffre Group, 278 Avenue de la Marne, Château rouge, 59700 Marcq en Baroeul, France. '2University of Bordeaux, UMR 5248, Bordeaux Sci Agro, Gradignan, France. ${ }^{3}$ Biofortis-Mérieux NutriSciences, Saint-Herblain, France. ${ }^{4}$ Paris 7 University and AP-HP, Hôpital Saint Antoine, Paris, France.

Received: 16 September 2015 Accepted: 23 November 2015

Published online: 03 December 2015 


\section{References}

1. Gavazzi G, Krause KH. Ageing and infection. Lancet Infect Dis. 2002;2(11): 659-66.

2. Panda A, Qian F, Mohanty S, van Duin D, Newman FK, Zhang L, et al. Age-associated decrease in TLR function in primary human dendritic cells predicts influenza vaccine response. J Immunol. 2010;184(5):2518-27. doi:10.4049/jimmunol.0901022.

3. Dace DS, Apte RS. Effect of senescence on macrophage polarization and angiogenesis. Rejuvenation Res. 2008;11(1):177-85. doi:10.1089/rej.2007.0614.

4. Fulop T, Le Page A, Fortin C, Witkowski JM, Dupuis G, Larbi A. Cellular signaling in the aging immune system. Curr Opin Immunol. 2014;29:105-11. doi:10.1016/j.coi.2014.05.007.

5. Jagger A, Shimojima Y, Goronzy JJ, Weyand CM. Regulatory T cells and the immune aging process: a mini-review. Gerontology. 2014;60(2):130-7. doi:10.1159/000355303

6. Goronzy JJ, Lee WW, Weyand CM. Aging and T-cell diversity. Exp Gerontol. 2007;42(5):400-6. doi:10.1016/j.exger.2006.11.016.

7. Frasca D, Diaz A, Romero M, Landin AM, Phillips M, Lechner SC, et al. Intrinsic defects in B cell response to seasonal influenza vaccination in elderly humans. Vaccine. 2010;28(51):8077-84. doi:10.1016/j.vaccine.2010.10.023.

8. Frasca D, Blomberg BB. B cell function and influenza vaccine responses in healthy aging and disease. Curr Opin Immunol. 2014;29:112-8. doi:10.1016/j.coi.2014.05.008.

9. Gibson KL, Wu YC, Barnett Y, Duggan O, Vaughan R, Kondeatis E, et al. B-cell diversity decreases in old age and is correlated with poor health status. Aging Cell. 2009;8(1):18-25. doi:10.1111/j.1474-9726.2008.00443.x.

10. Evans P, Der G, Ford G, Hucklebridge F. Hunt K, Lambert S. Social class, sex, and age differences in mucosal immunity in a large community sample. Brain Behav Immun. 2000;14(1):41-8. doi:10.1006/brbi.1999.0571.

11. Miletic ID, Schiffman SS, Miletic VD, Sattely-Miller EA. Salivary IgA secretion rate in young and elderly persons. Physiol Behav. 1996;60(1):243-8.

12. Ohland CL, Macnaughton WK. Probiotic bacteria and intestinal epithelial barrier function. Am J Physiol Gastrointest Liver Physiol. 2010;298(6):G807-19. doi:10.1152/ajpgi.00243.2009.

13. Claesson MJ, Cusack S, O'Sullivan O, Greene-Diniz R, de Weerd H, Flannery E, et al. Composition, variability, and temporal stability of the intestinal microbiota of the elderly. Proc Natl Acad Sci U S A. 2011;108 Suppl 1: 4586-91. doi:10.1073/pnas.1000097107.

14. Duncan SH, Flint HJ. Probiotics and prebiotics and health in ageing populations. Maturitas. 2013;75(1):44-50. doi:10.1016/j.maturitas.2013.02.004

15. Gill HS, Rutherfurd KJ, Cross ML, Gopal PK. Enhancement of immunity in the elderly by dietary supplementation with the probiotic Bifidobacterium lactis HN019. Am J Clin Nutr. 2001;74(6):833-9.

16. Kotani Y, Shinkai S, Okamatsu H, Toba M, Ogawa K, Yoshida H, et al. Oral intake of Lactobacillus pentosus strain b240 accelerates salivary immunoglobulin A secretion in the elderly: A randomized, placebo-controlled, double-blind trial. Immun Ageing. 2010;7:11. doi:10.1186/1742-4933-7-11.

17. Lahtinen SJ, Forssten S, Aakko J, Granlund L, Rautonen N, Salminen S, et al. Probiotic cheese containing Lactobacillus rhamnosus HN001 and Lactobacillus acidophilus NCFM(R) modifies subpopulations of fecal lactobacilli and Clostridium difficile in the elderly. Age (Dordr). 2012;34(1): 133-43. doi:10.1007/s11357-011-9208-6.

18. FAO/WHO. Health and Nutrition Properties of Probiotics in Food including Powder Milk with Live Lactic Acid Bacteria Report of a Joint FAO/WHO Expert Consultation on Evaluation of Health and Nutritional Properties of Probiotics in Food including Powder Milk with Live Lactic Acid Bacteria. Report 2001. Cordoba, Argentina 1-4 October 2001. Report No.: 0254-4725

19. Fukushima Y, Miyaguchi S, Yamano T, Kaburagi T, lino H, Ushida K, et al. Improvement of nutritional status and incidence of infection in hospitalised, enterally fed elderly by feeding of fermented milk containing probiotic Lactobacillus johnsonii La1 (NCC533). Br J Nutr. 2007:98(5):969-77. doi:10.1017/S0007114507764723.

20. Guillemard E, Tondu F, Lacoin F, Schrezenmeir J. Consumption of a fermented dairy product containing the probiotic Lactobacillus case $\mathrm{DN}-114001$ reduces the duration of respiratory infections in the elderly in a randomised controlled trial. Br J Nutr. 2010;103(1):58-68. doi:10.1017/ S0007114509991395

21. Turchet $P$, Laurenzano $M$, Auboiron S, Antoine JM. Effect of fermented milk containing the probiotic Lactobacillus casei DN-114001 on winter infections in free-living elderly subjects: a randomised, controlled pilot study. J Nutr Health Aging. 2003;7(2):75-7.
22. Makino S, Ikegami S, Kume A, Horiuchi H, Sasaki H, Orii N. Reducing the risk of infection in the elderly by dietary intake of yoghurt fermented with Lactobacillus delbrueckii ssp. bulgaricus OLL1073R-1. Br J Nutr. 2010;104(7): 998-1006. doi:10.1017/S000711451000173X.

23. Mane J, Pedrosa E, Loren V, Gassull MA, Espadaler J, Cune J, et al. A mixture of Lactobacillus plantarum CECT 7315 and CECT 7316 enhances systemic immunity in elderly subjects. A dose-response, double-blind, placebocontrolled, randomized pilot trial. Nutr Hosp. 2011;26(1):228-35.

24. Boge T, Remigy M, Vaudaine S, Tanguy J, Bourdet-Sicard R, van der Werf S. A probiotic fermented dairy drink improves antibody response to influenza vaccination in the elderly in two randomised controlled trials. Vaccine. 2009; 27(41):5677-84. doi:10.1016/j.vaccine.2009.06.094.

25. Bosch M, Mendez M, Perez M, Farran A, Fuentes MC, Cune J. Lactobacillus plantarum CECT7315 and CECT7316 stimulate immunoglobulin production after influenza vaccination in elderly. Nutr Hosp. 2012;27(2): 504-9. doi:10.1590/S0212-16112012000200023.

26. Davidson LE, Fiorino AM, Snydman DR, Hibberd PL. Lactobacillus GG as an immune adjuvant for live-attenuated influenza vaccine in healthy adults: a randomized double-blind placebo-controlled trial. Eur J Clin Nutr. 2011; 65(4):501-7. doi:10.1038/ejcn.2010.289.

27. Van Puyenbroeck K, Hens N, Coenen S, Michiels B, Beunckens C, Molenberghs $\mathrm{G}$, et al. Efficacy of daily intake of Lactobacillus casei Shirota on respiratory symptoms and influenza vaccination immune response: a randomized, double-blind, placebo-controlled trial in healthy elderly nursing home residents. Am J Clin Nutr. 2012;95(5): 1165-71. doi:10.3945/ajen.111.026831.

28. Cutting SM. Bacillus probiotics. Food Microbiol. 2011;28(2):214-20. doi:10.1016/j.fm.2010.03.007.

29. Hong HA, le Duc H, Cutting SM. The use of bacterial spore formers as probiotics. FEMS Microbiol Rev. 2005;29(4):813-35. doi:10.1016/j.femsre.2004.12.001.

30. Marseglia GL, Tosca M, Cirillo I, Licari A, Leone M, Marseglia A, et al. Efficacy of Bacillus clausii spores in the prevention of recurrent respiratory infections in children: a pilot study. Ther Clin Risk Manag. 2007;3(1):13-7.

31. Mazza P. The use of Bacillus subtilis as an antidiarrhoeal microorganism. Boll Chim Farm. 1994;133(1):3-18.

32. Ratna Sudha M, Yelikar KA, Deshpande S. Clinical Study of Bacillus coagulans Unique IS-2 (ATCC PTA-11748) in the Treatment of Patients with Bacterial Vaginosis. Indian J Microbiol. 2012;52(3):396-9. doi:10. 1007/s12088-011-0233-z

33. La Rosa M, Bottaro G, Gulino N, Gambuzza F, Di Forti F, Ini G, et al. Prevention of antibiotic-associated diarrhea with Lactobacillus sporogens and fructo-oligosaccharides in children. A multicentric double-blind vs placebo study. Minerva Pediatr. 2003;55(5):447-52.

34. Tompkins TA, Xu X, Ahmarani J. A comprehensive review of post-market clinical studies performed in adults with an Asian probiotic formulation. Benef Microbes. 2010;1(1):93-106. doi:10.3920/BM2008.1005

35. Foligne B, Deutsch SM, Breton J, Cousin FJ, Dewulf J, Samson M, et al. Promising immunomodulatory effects of selected strains of dairy propionibacteria as evidenced in vitro and in vivo. Appl Environ Microbiol. 2010;76(24):8259-64. doi:10.1128/AEM.01976-10.

36. Cross ML. Immunoregulation by probiotic lactobacilli: pro-Th1 signals and their relevance to human health. Clin Appl Immunol Rev. 2002;3(3):115-25. doi:10.1016/S1529-1049(02)00057-0.

37. Howarth GS, Wang $H$. Role of endogenous microbiota, probiotics and their biological products in human health. Nutrients. 2013:5(1):58-81. doi:10.3390/nu5010058.

38. Rijkers GT, Bengmark S, Enck P, Haller D, Herz U, Kalliomaki M, et al. Guidance for substantiating the evidence for beneficial effects of probiotics: current status and recommendations for future research. J Nutr. 2010;140(3):671S-6S. doi:10.3945/jn.109.113779.

39. Sanchez B, Arias S, Chaignepain S, Denayrolles M, Schmitter JM, Bressollier P, et al. Identification of surface proteins involved in the adhesion of a probiotic Bacillus cereus strain to mucin and fibronectin. Microbiology 2009:155(Pt 5):1708-16. doi:10.1099/mic.0.025288-0.

40. Pinchuk IV, Bressollier P, Verneuil B, Fenet B, Sorokulova IB, Megraud F, et al. In vitro anti-Helicobacter pylori activity of the probiotic strain Bacillus subtilis 3 is due to secretion of antibiotics. Antimicrob Agents Chemother. 2001;45(11):3156-61. doi:10.1128/AAC.45.11.3156-3161.2001.

41. Urdaci MC, Pinchuk I. Antimicrobial activity of Bacillus probiotics. In: Ricca E, Henriques AO, Cutting SM, editors. Bacterial spore formers - Probiotics and emerging applications. Norfolk, UK: Horizon Bioscience; 2004. p. 171-82. 
42. Fujiya M, Musch MW, Nakagawa Y, Hu S, Alverdy J, Kohgo Y, et al. The Bacillus subtilis quorum-sensing molecule CSF contributes to intestinal homeostasis via OCTN2, a host cell membrane transporter. Cell Host Microbe. 2007;1(4):299-308. doi:10.1016/j.chom.2007.05.004.

43. Hosoi T, Hirose R, Saegusa S, Ametani A, Kiuchi K, Kaminogawa S. Cytokine responses of human intestinal epithelial-like Caco-2 cells to the nonpathogenic bacterium Bacillus subtilis (natto). Int J Food Microbiol. 2003;82(3):255-64.

44. Ciprandi G, Tosca MA, Milanese M, Caligo G, Ricca V. Cytokines evaluation in nasal lavage of allergic children after Bacillus clausii administration: a pilot study. Pediatr Allergy Immunol. 2004;15(2):148-51. doi:10.1046/j.1399-3038. 2003.00102.x.

45. Urdaci MC, Bressollier P, Pinchuk I. Bacillus clausii probiotic strains: antimicrobial and immunomodulatory activities. J Clin Gastroenterol. 2004;38(6 Suppl):S86-90

46. Fiorini G, Cimminiello C, Chianese R, Visconti GP, Cova D, Uberti T, et al, Bacillus subtilis selectively stimulates the synthesis of membrane bound and secreted IgA. Chemioterapia. 1985:4(4):310-2.

47. Albers R, Antoine JM, Bourdet-Sicard R, Calder PC, Gleeson M, Lesourd B, et al. Markers to measure immunomodulation in human nutrition intervention studies. Br J Nutr. 2005;94(3):452-81. doi:10.1079/BJN20051469.

48. Huang JM, La Ragione RM, Nunez A, Cutting SM. Immunostimulatory activity of Bacillus spores. FEMS Immunol Med Microbiol. 2008;53(2):195-203. doi:10.1111/j.1574-695X.2008.00415.x.

49. Mehrad B, Standiford TJ. Role of cytokines in pulmonary antimicrobial host defense. Immunol Res. 1999;20(1):15-27. doi:10.1007/BF02786504.

50. Sadler AJ, Williams BR. Interferon-inducible antiviral effectors. Nat Rev Immunol. 2008;8(7):559-68. doi:10.1038/nri2314.

51. Hori T, Kiyoshima J, Shida K, Yasui H. Augmentation of cellular immunity and reduction of influenza virus titer in aged mice fed Lactobacillus casei strain Shirota. Clin Diagn Lab Immunol. 2002;9(1):105-8.

52. Park MK, Ngo V, Kwon YM, Lee YT, Yoo S, Cho YH, et al. Lactobacillus plantarum DK119 as a probiotic confers protection against influenza virus by modulating innate immunity. PLOS ONE. 2013;8(10):e75368. doi:10.1371/journal.pone.0075368.

53. Fukushima Y, Kawata Y, Hara H, Terada A, Mitsuoka T. Effect of a probiotic formula on intestinal immunoglobulin A production in healthy children. Int J Food Microbiol. 1998;42(1-2):39-44

54. Kabeerdoss J, Devi RS, Mary RR, Prabhavathi D, Vidya R, Mechenro J, et al Effect of yoghurt containing Bifidobacterium lactis Bb12(R) on faecal excretion of secretory immunoglobulin A and human beta-defensin 2 in healthy adult volunteers. Nutr J. 2011;10:138. doi:10.1186/1475-2891-10-138.

55. Brandtzaeg P. Mucosal immunity: induction, dissemination, and effector functions. Scand J Immunol. 2009;70(6):505-15. doi:10.1111/j.1365-3083. 2009.02319.x.

56. Lycke N, Erlandsson L, Ekman L, Schon K, Leanderson T. Lack of J chain inhibits the transport of gut $\lg A$ and abrogates the development of intestinal antitoxic protection. J Immunol. 1999;163(2):913-9.

57. Moyad MA, Robinson LE, Zawada ET, Kittelsrud J, Chen DG, Reeves SG, et al. Immunogenic yeast-based fermentate for cold/flu-like symptoms in nonvaccinated individuals. J Altern Complement Med. 2010;16(2):213-8. doi:10.1089/acm.2009.0310.

58. Jensen GS, Patterson KM, Barnes J, Schauss AG, Beaman R, Reeves SG, et al A Double-Blind Placebo-Controlled, Randomized Pilot Study: Consumption of a High-Metabolite Immunogen from Yeast Culture has Beneficial Effects on Erythrocyte Health and Mucosal Immune Protection in Healthy Subjects. Open Nutr J. 2008;2:68-75.

59. Jemmott 3rd JB, Borysenko JZ, Borysenko M, McClelland DC, Chapman R, Meyer D, et al. Academic stress, power motivation, and decrease in secretion rate of salivary secretory immunoglobulin $\mathrm{A}$. Lancet. 1983;1(8339):1400-2

60. Mackinnon LT, Chick TW, van As A, Tomasi TB. The effect of exercise on secretory and natural immunity. Adv Exp Med Biol. 1987;216A:869-76.

61. King S, Glanville J, Sanders ME, Fitzgerald A, Varley D. Effectiveness of probiotics on the duration of illness in healthy children and adults who develop common acute respiratory infectious conditions: a systematic review and meta-analysis. Br J Nutr. 2014;112(1):41-54. doi:10.1017/S0007114514000075.

62. Pinchuk IV, Bressollier P, Sorokulova IB, Verneuil B, Urdaci MC. Amicoumacin antibiotic production and genetic diversity of Bacillus subtilis strains isolated from different habitats. Res Microbiol. 2002;153(5): 269-76. doi:10.1016/S0923-2508(02)01320-7.

\section{Submit your next manuscript to BioMed Central and we will help you at every step:}

- We accept pre-submission inquiries

- Our selector tool helps you to find the most relevant journal

- We provide round the clock customer support

- Convenient online submission

- Thorough peer review

- Inclusion in PubMed and all major indexing services

- Maximum visibility for your research

Submit your manuscript at www biomedcentral.com/submit 